\title{
Direito positivo, miséria social e violência no capitalismo globalizado
}

\section{Positive law, social misery and violence in globalized capitalism}

\author{
Antônio Roberto Xavier ${ }^{a}$ \\ (D) https://orcid.org/0000-0002-3018-2058 \\ Eduardo Ferreira Chagas ${ }^{b}$ \\ (D) https://orcid.org/0000-0003-1957-6117 \\ Edilberto Cavalcante Reisc \\ (D) https://orcid.org/0000-0003-3156-7387
}

\begin{abstract}
Resumo: $O$ presente artigo tem como objetivo principal demonstrar como o Estado moderno, através do sistema econômico capitalista e da globalização neoliberal, tem efetivado o processo de expropriação de forma deliberada, provocando miséria social e fomentando a violência e a criminalidade em larga escala. $O$ texto também mostra que o Estado moderno utiliza-se das ciências jurídicas para coibir e ignorar as situações sociais de trabalhadores sem emprego.

Palavras-chave: Capitalismo. Globalização. Violência. Ciências jurídicas.
\end{abstract}

\begin{abstract}
The main objective of this article is to demonstrate how the modern state, through the economic system, capitalist and neoliberal globalization, effectively or deliberately expropriation, provoking social misery and fomenting violence and crime on a large scale. The text also shows that the modern state uses legal sciences to curb and ignore the social situations of workers without jobs.
\end{abstract}

Keywords: Capitalism. Globalization. Violence. Legal Sciences. 


\section{Introdução}

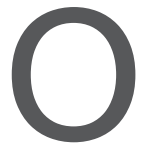

presente texto traz à tona um debate atual e necessário, incluindo várias reflexões sobre a atual realidade social. $O$ estudo analisa dialeticamente a problemática da miséria social em larga escala e, consequentemente, o aumento da violência e da criminalidade no âmbito do sistema capitalista globalizado, apoiado pelas ciências jurídicas, sobretudo pelo direito penal positivista.

A vulnerabilidade com que se apresenta a sociedade atual frente ao poder real das práticas delituosas demonstra medo, desânimo e descrença quanto a um futuro promissor. $\mathrm{O}$ abandono de valores mais sublimes que devem fazer parte da mente e do coração humanos cresce assustadoramente, somado à perda de princípios éticos/morais em face do desejo egocêntrico por bens materiais e do fetiche do consumo a qualquer custo.

Parece paradoxal, mas, na proporção em que o ser humano transforma o meio natural e descobre evolutivamente novas técnicas produtivas e aperfeiçoa outras, a violência criminal também tem se aperfeiçoado, não apenas devido ao avanço ou ao progresso tecnológico em si, mas principalmente por razões da intelectualidade humana, de planejamento, cálculos e premeditações constantes, levadas para práticas da violência e da banalização da vida.

Indubitavelmente, a ideia de criação do Estado, com o propósito de proteger seus súditos, não tem conseguido controlar o oponente da paz: a violência. $\mathrm{O}$ aumento desta e da criminalidade no mundo, operando associadamente com as mais avançadas tecnologias, compromete o tecido social humano, bem como o Estado moderno, ameaçando, inclusive, sua soberania e razão de ser.

Como se sabe, o Estado moderno foi originariamente erigido através de um pacto social firmado para proteger seus cidadãos e para manter a ordem social, evitando, assim, a guerra de todos contra todos. Esse foi, em princípio, o propósito original da criação do Estado moderno. A falta de virtudes do homem para consigo e para com o seu semelhante e a inobservância ou a falta do cumprimento das funções delegadas ao Estado para solucionar os litígios pacificamente em sociedade têm tornado os espaços 
sociais de convivência, sobretudo os urbanos, em campos propícios para o aumento exacerbado da violência, da conflitualidade e da destruição da vida (Hobbes, 1983).

Nesse sentido, o Estado moderno, como detentor do poder e do monopólio da violência, não tem conseguido cumprir sua missão de assegurar à população a proteção suficiente e necessária para a preservação da vida. Sendo assim, a quebra do pacto original firmado por cada um ao elencar o Estado como ser artificial para arbitrar pacificamente os litígios tem causado a falta de uma convivência harmoniosa que eleve a paz duradoura (Weber, 1982).

O não cumprimento do contrato social proposto, por exemplo, por Rousseau (2006), em que o homem passa do estado de natureza ao estado social civil, desenvolvendo a tolerância e buscando a justiça humana, tem culminado com a banalização do sentido da vida e, consequentemente, com sua eliminação. Por conta desse fato, o homem (em sentido genérico) tem se tornado, na expressão hobbesiana, lobo do próprio homem, retornando e vivendo num estado de natureza, conflito e guerra constante de todos contra todos, chegando ao extremo da erradicação da própria vida e da vida de seu semelhante, cuja mola propulsora e mentora tem sido o sistema econômico, mercantilizador do ser humano e de sua liberdade: o capitalismo (Hobbes, 1983).

\section{Capitalismo no Estado-nação e positivismo jurídico}

Embora as pilastras do Estado moderno tenham sido fincadas ainda no século XVI, sua consolidação somente chega ao ápice com a primeira Revolução Industrial, na segunda metade do século XVIII, que potencializou uma nova estrutura econômica, cuja consequência imediata foi a exigência de uma reorganização econômica, social, política e cultural, bem como meios de produção e forças produtivas especializadas e qualificadas. Concomitantemente a essa modernidade, expandiu-se e foi fortalecido um sistema econômico, se não novo, com nova roupagem: o capitalismo, o qual foi pautado no liberalismo e nos princípios fisiocráticos 
do laissez faire, laissez passer, le monde va de lui même ${ }^{1}$ do século XVI, que reivindicava, incondicionalmente, o afastamento do Estado da intervenção na economia.

Para o estabelecimento dessa ordem reivindicada pelo Estado-nação burguês, delegou-se a responsabilidade aos ditames da sociedade disciplinar, com base nos códigos e normatizações repressivos e punitivos.

Com o advento do estatuto jurídico da sociedade burguesa a partir do Estado moderno definido pelos pensadores iluministas, ficou assegurada a separação dos poderes do Estado em Legislativo, Executivo e Judiciário, como forma de evitar abusos e tiranias dos governantes praticados no antigo regime absolutista, no qual os monarcas agiam como se fossem a própria lei, executando ou queimando seus desafetos. Com o surgimento das ideias humanitárias do Iluminismo no Estado moderno e, posteriormente, no Estado-nação liberal, a razão prevalecia. Portanto, os governantes deveriam agir com base no racionalismo humano, sob o manto da lei. Influenciado pela proposta lockeana de um Poder Legislativo, Montesquieu definirá a arte de legislar como instrumento capaz de evitar as contradições dos códigos e de adequar as leis à natureza e aos princípios dos governos.

Além disso, o projeto de Estado liberal que preconizou a responsabilidade pela proteção patrimonial e das liberdades individuais das pessoas, tutelando a ordem social para que o indivíduo não se sentisse no direito de fazer justiça com as "próprias mãos", até o atual estado de coisas é apenas quimera. $\mathrm{O}$ Estado, além de detentor legal do monopólio da violência, arrolou-se como legítimo detentor do poder capaz de manter a ordem social, impondo direitos e deveres aos indivíduos, determinando a forma jurídica que deve prevalecer através de delegações aos poderes e às autoridades legítima e legalmente constituídas (Castel, 2005; Locke, 1983; Weber, 1982).

Combinando com o capitalismo e a modernidade, o projeto das ciências jurídicas, sobretudo as penais, cujo ideário é positivista, baseou-se na insustentável tese de que o fenômeno da criminalidade na sociedade industrializada e pós-industrializada era resultado de desvio de padrões

1 Traduzindo livremente: “Deixai fazer, deixai passar, o mundo caminha por ele mesmo”. 
morais, os quais deveriam ser analisados pela observância de causa e efeito para enquadramento punitivo de acordo com as previsões objetivas da lei.

O fato é que as ciências jurídicas, especificamente o direito penal, não questionam ou não se interessam por saber se há ou não causas sociais para eventuais desvios da norma-padrão. Aceitam pacífica e consensualmente o crime como fruto do princípio da diversidade patológica do homem delinquente e da disfuncionalidade do comportamento criminal, e a pena serve como fim de resposta justa e útil por si só, sem, contudo, importarem-se com as condições sociais ou materiais de existência dos supostos infratores em razão das leis preestabelecidas.

Nesse sentido, a efetivação do direito penal positivo tem sido incapaz tanto de frear o aumento das violências e da criminalidade como também de proporcionar efetivamente medidas de prevenção, de controle e de combate. Em contrapartida, a concepção marxista elevou o direito, sobretudo o penal, ao nível da superestrutura social, como idealizador da afirmação do sistema capitalista de maneira injusta e repressiva às classes trabalhadoras. Desse modo, conforme Gomes, Prado e Douglas (2000, p. 108), o direito penal tem sido utilizado "como instrumento de controle dos segmentos sociais desfavorecidos ou descontentes com a ideologia peculiar a este tipo de capitalismo".

Apesar do desenvolvimento da criminologia crítica nos sistemas jurídicos contemporâneos, essa não tem sido suficiente nem eficiente o bastante para enquadrar o crime dentro da justiça real de incriminação, tampouco de freá-lo adequadamente. Isso é resultado da enorme desigualdade e exclusão sociais, aspectos desencadeados por um sistema cada vez mais agudo, agonizante e paradoxal: o capitalismo. Sob esse prisma, segundo Coggiola (2002, p. 489), foi delegado às grandes massas de trabalhadores "a miséria social, o desemprego, a destruição de conquistas trabalhistas e o aviltamento do trabalho, a flexibilidade e a precarização, a exploração ímpar das nações oprimidas" e, consequentemente, todo tipo de violência e criminalidade.

Indubitavelmente, o avanço do capitalismo e a tentativa imposta pelo mercado de uma sociedade global, conforme Ianni (2002), têm produzido e intensificado desigualdades sociais, econômicas e culturais em escala mundial, nacional, regional e local. Além disso, o processo de globalização, 
aquecido pela política mercadológica neoliberal, desenvolve a interdependência e a desintegração das sociedades, gerando desigualdades, tensões e antagonismos, debilitando o Estado-nação e/ou redefinindo as condições hegemônicas de sua soberania.

Nessa esteira, consoante Ianni (2002), quando o Estado-nação se debilita, em do alcance e da intensidade do processo globalizante neoliberal, surgem outras realidades e características de uma sociedade globalizada, com novas relações, processos e estruturas, fazendo emergir modificações substanciais nas condições de trabalho, nos modos de ser, sentir, pensar e imaginar, pois as práticas de discriminação, vulnerabilidade e exploração sociais no moderno capitalismo têm no direito penal um instrumento auxiliador de legitimação, sendo também esse direito reacionário às reivindicações das classes sociais por melhores condições de vida, seguridade social, emprego, educação, saúde e segurança civil. Porém, mesmo com a instalação do Estado-nação ${ }^{2}$ liberal e com a Declaração Universal dos Direitos do Homem e do Cidadão, isso não redundou na emancipação ou na garantia da cidadania ativa aos trabalhadores, haja vista que, conforme Castel (2003, p. 271), "em nome do direito que deve ser imposto a todos, os proletários devem ser de fato excluídos da cidadania plena”.

Conforme Ianni (2002, p. 111), a cidadania do homem mundial "está apenas em esboço, pensada, prometida, imaginada”. Deste modo, as organizações governamentais, tais como a Organização das Nações Unidas (ONU), a Organização das Nações Unidas para a Educação, a Ciência e a Cultura (Unesco) e outras, inclusive não governamentais, pouco podem fazer para

2 "Para captar mais precisamente o devir dessa forma de Estado no decorrer do século XIX e analisar as tomadas de posição e as concepções do poder que ela suscitou, é preciso voltar atrás e interrogar essa experiência e os textos partidários, programáticos ou críticos dos que participaram dos eventos [...]. Doravante, o Estado-nação constitui o quadro obrigatório da existência social: ele é a realidade política por excelência, em torno da qual se organizam os atos históricos [...], surgido certamente com a Restauração Inglesa de 1690, afirma-se fortemente com a Revolução Americana de 1776 e com a Revolução Francesa (e, para essa, desde 1790, quando ela é ainda 'realista'). E esse Estado-nação é ainda hoje a trama do mundo político, quaisquer que sejam suas diversidades e novidades" (Châtelet, Duhamel e Pisier-Kouchner, 2000, p. 85-86). 
“concretizar os princípios da liberdade e igualdade em escala mundial". Até mesmo um dos documentos considerados um marco para o mundo, logo após o holocausto da Segunda Guerra Mundial, a “Declaração Universal dos Direitos do Homem, promulgada pela ONU em 1948, permanece como uma declaração de intenções, de ideais, a despeito da sua importância social, política, econômica e cultural".

Desse modo, é possível compreender como uma determinação judicial pode apresentar-se plenamente fundamentada e coerente com as circunstâncias e instituições existentes e ser, no entanto, irracional e injusta em si e para si. Nesse prisma, é relevante esclarecer que, mantendo-se indiferente à realidade social, o direito penal positivista assegura a punição com base no que preceitua a lei, indiferente e independentemente da situação social de cada pessoa.

Indubitavelmente, o avanço do capitalismo e a tentativa imposta pelo mercado de uma sociedade global têm produzido uma escalada crescente de: desigualdades sociais, econômicas, políticas e culturais em âmbito mundial, principalmente nas chamadas economias periféricas, cuja compatibilidade é inviável no processo de globalização neoliberal. Esse processo, no qual se desenvolvem a interdependência, a integração e a dinamização das sociedades nacionais, produz desigualdades, tensões e antagonismos, debilita o Estado-nação ou redefine as condições de sua soberania, provocando o desenvolvimento de diversidades e contradições em escala mundial, nacional e regional.

Com isso, o capitalismo e a pretensa globalização neoliberal, com seu fetichismo pelo mercado e pelos bens materiais, tornam-se antagônicos em si mesmos em razão da insana coisificação do ser humano. Neste sentido, segundo Kurz (2010, p. 37) “Tanto do ponto de vista material quanto em termos ideais, o capitalismo aniquila-se a si mesmo ao se fazer triunfante. Quão mais brutalmente essa forma de reprodução convertida em sociedade global devasta o mundo, tanto mais inflige ferimentos a si própria, soterrando sua própria existência".

Nesse sentido, quando o Estado-nação se debilita, em virtude do alcance e da intensidade do processo globalizante, surgem outras realidades, 
características de uma sociedade global com novas relações, processos e estruturas. Em consequência disso, emergem também modificações substanciais nas condições de trabalho, nos modos de ser, sentir, pensar e imaginar.

Com efeito, se, por um lado, a globalização é um fenômeno produtor de intercâmbio social, econômico, político, religioso e cultural, costurado em um emaranhado de complexidade, por outro, em vez de uniformidade, acirra a diferença e a fragmentação, fragilizando as relações e a coesão social. No âmago dessa fragmentação cultural e social, a criminalidade e a violência, por sua vez, traduzem-se em atos defensivos e contraofensivos de grupos que anseiam por afirmar suas identidades política, econômica e culturalmente. Nesse caso, conforme Velho (2002, p. 26-27), "somente governantes legitimados democraticamente pela sociedade civil e voltados para os direitos humanos terão alguma possibilidade de exercer com sucesso o poder e a força contra a criminalidade".

Wieviorka (1997) aduz que a violência tende a se alastrar nesse terreno de fraturas sociais, no qual não é perceptível um poder ou uma fórmula política que seja capaz de frear os conflitos e antagonizações gerados e alimentados pelos sentimentos das injustiças, da discriminação e da exclusão produzidos pelo capitalismo na esfera da globalização neoliberal.

Velho (2002) também reafirma que o conflito, a tensão e a diferença fazem parte da vida social deste tempo, porém são impossibilitados da troca e da reciprocidade, gerando obstáculos socioculturais gravíssimos e fazendo emergir a violência difusa dentro de pequenos grupos, que evoluem gradativamente em redes, atingindo de maneira frontal todo o tecido social.

Por outro lado, o tardio capitalismo, ou capitalismo desorganizado, expropriador e marginalizante das grandes massas, tornou-se uma força econômica e culturalmente hegemônica, que se baseia na ideologia de naturalizar o mercado e na exploração econômica, visando à maximização da rentabilidade. Nesse tipo de capitalismo, a acumulação rentável é ilimitada e produz desigualdade real e jurídica entre pessoas, entre amigos e parentes, entre povos e nações, fomentando o conflito gerador de violências e de criminalidade nas formas física e psicológica. 
Sob esse viés, à luz de Mendonça (2008), o fetiche mercadológico de tudo e de todos, objetivando o lucro acima de tudo, fomentado pela globalização neoliberal, tem contribuído sistematicamente para o aumento da violência e novas formas de criminalidade, em função da produção de desigualdades sociais acirradas que assolam as nações, os grupos e as coletividades, tornando comunidades inteiras anômicas, destruindo valores, princípios e referenciais éticos e morais imprescindíveis à sobrevivência harmoniosa da sociedade.

Diante desse quadro de perspectivas rebaixadas, as ciências penais, sobretudo o direito penal, buscam, desatinadamente e sem êxito, passar a sensação de que o problema da criminalidade será resolvido em conformidade com os ditames da lei com vistas aos interesses sociais e da cidadania. Porém, conforme Gomes, Prado e Douglas (2000, p. 113), "por maiores que sejam os sucessos das suas múltiplas análises, [...] a sociologia crítica do direito penal não logrou até o momento vencer as barreiras culturais do individualismo exacerbado, que dá à questão criminal o tom de sua difusão, aparentemente, não controlável e violenta".

Com efeito, as práticas de discriminação, vulnerabilidade e exploração sociais no moderno capitalismo têm no direito penal um instrumento auxiliador de legitimação, sendo também esse direito reacionário às reivindicações das classes sociais por melhores condições de vida, seguridade social, emprego, educação, saúde e segurança civil. Contudo, como esclarece Castel (2003, p. 271), mesmo com a instalação do Estado-nação liberal e com a Declaração Universal dos Direitos do Homem e do Cidadão, isso não redundou na emancipação ou na garantia da cidadania ativa aos trabalhadores, visto que, "em nome do direito que deve ser imposto a todos, os proletários devem ser de fato excluídos da cidadania plena”.

Desse modo, concorda-se com Hegel (2003), quando postula que uma determinação jurídica pode apresentar-se plenamente fundamentada e coerente com as circunstâncias e instituições existentes e ser, no entanto, irracional e injusta em si e para si.

A agudização da globalização e de sua pretensão de transformar o mundo numa aldeia global atingiu em cheio as ciências penais. Dessa forma, 
as práticas judiciárias, que sempre apareceram como imperturbáveis, sofreram alterações legislativas, sobretudo para proteger interesses de classes dominantes e reprimir duramente aqueles que se desviarem das normas do estatuto jurídico burguês.

Concordamos com Bourdieu (2002) quando classifica ciência jurídica como um sistema fechado e autônomo, produtor de violência simbólica, $a$ priori, cuja dinâmica de desenvolvimento só pode ser compreendida no meio interno. Isso se constitui na reivindicação de uma autonomia absoluta do pensamento e da ação jurídicos, ou seja, num modo específico, independente e alheio ao peso histórico, social e/ou psicológico que possam envolver as circunstâncias.

Segundo ainda Bourdieu (2002), essa é a meta da "teoria pura do direito" tentada por Kelsen, cujo esforço é o da construção de um corpo de juristas, de doutrinas e de regras completamente independentes dos constrangimentos e das pressões sociais, tendo por si só seu próprio fundamento.

Nessa ótica, as ideologias dominantes dos sistemas simbólicos (como instrumentos de conhecimento e de comunicação) servem a interesses particulares, que tendem a apresentar-se como interesses universais, comuns ao conjunto do grupo para a integração fictícia da sociedade no seu conjunto. Consoante Bourdieu (2002, p. 11), "para assegurar a dominação de uma classe sobre outra (violência simbólica), dando o reforço da sua própria força às relações de força que as fundamentam e contribuindo, assim, segundo a expressão de Weber, para a 'domesticação dos dominados'”.

As tomadas de posição ideológica dos dominantes se efetivam por meio de estratégias de reprodução dominadoras, reforçando, dentro da classe e fora dela, a crença na legitimidade da dominação. Nesse sentido, as ciências jurídicas, sobretudo o direito penal, enquadram-se como "sistemas simbólicos" a serviço das ideologias dominantes, como instrumentos estruturados e estruturantes de comunicação e de conhecimento que cumprem a função política de dominação aparentemente legal, sem se importar com as questões materiais de existência da grande maioria da população de trabalhadores que gradativamente seguem em direção à miséria social, produtora de violência e criminalidade como últimas consequências. 


\section{Miséria social, violência e criminalidade no âmbito do capitalismo}

Os sistemas simbólicos de dominação conseguem a desmobilização (falsa consciência) das classes dominadas. Em consequência, o sistema capitalista globalizado e neoliberal segue produzindo miséria e excludência de forma letal às classes trabalhadoras e historicamente alijadas dos bens de produção, sejam materiais e/ou intelectuais. No âmago desse fosso social de miséria, crescem a violência e a criminalidade como sobras ou alternativas maléficas às grandes multidões de trabalhadores sem trabalho chamados de inúteis para o mundo seletivo do capitalismo globalizado e neoliberal.

Deste modo, segundo Moraes (2001), as constantes alterações políticas, econômicas e sociais, exigidas por um sistema capitalista vulnerável, volátil e decadente, e a degradação de princípios e valores ético-morais, tradicionalmente fortificadores da coesão social, têm produzido exclusões em escala global, nacional, regional e local. A produção da miséria social em escala global é evolutivamente acentuada em razão de desejos desenfreados, ambições, individualismo, egoísmo, concentração de renda tanto de pessoas como de blocos econômicos e nações. É nesse terreno de desigualdades e incertezas que tem se proliferado um campo multifacetado de violência e criminalidade, atingindo mortalmente povos, nações, comunidades e grupos vulneráveis social e economicamente.

A miséria social e o aumento da violência e da criminalidade complexa e difusa não são consequências apenas do capitalismo do Estado moderno. Entretanto, os processos de destruição e de pauperização de um número crescente de povos, comunidades e países, arruinados política, econômica e socialmente, têm fomentado e propiciado o alastramento de uma violência criminal sem precedentes na história. É previsível afirmar, como já fez Kurz (1993, p. 104), que: "se não for feito o suficiente para acabar logo com a pobreza, a miséria e o desespero no mundo, deslizes demográficos e catástrofes ecológicas provocarão tensões e violência, guerras e atos de terror de cujo alastramento nenhum país do globo estaria a salvo".

Indubitavelmente, na atual realidade, é perceptível e, ao mesmo tempo, inegável que a violência e a criminalidade difusas assumiram dimensões 
e contornos indecifráveis e assustadores em todo o planeta. A irracionalidade humana levou o século XX e o início do atual, o XXI, a um "banho de sangue", com a morte indiscriminada de seres humanos, em guerras e distúrbios civis internos, ou em guerras, ondas de terror e massacres coletivos praticados por países poderosos sobre nações, povos, comunidades, coletividades e grupos sociais.

O fato é que, na atual sociedade globalizada, globalizante e interconectada real e virtualmente, a disseminação e a produção da violência criminal evoluíram numa escala crescente, em que tudo é válido em nome do poder, do capital expropriador e do bem material, a despeito da degradação e da banalização da vida e dos valores humanos. A busca insana pelo poder, riqueza e fama é uma real característica de uma sociedade que se tornou volátil, sem valores fixos, efêmera e alienada por prazeres carnais concretos que satisfaçam o ego ou a visão.

Dentro desse panorama, o crime tem atingido graus e índices alarmantes em todos os mais remotos e longínquos locais do mundo. Não dispondo de uma política mediadora de resoluções sociais por parte dos países ricos em detrimento de regiões empobrecidas pela exploração do colonialismo e neocolonialismo, restou ao braço criminoso assumir tal função.

Pelo visto, faz-se mister reinventar a política, partindo de uma nova dialética entre democracia formal e democracia social, cuja síntese produtiva signifique novas formas de organização, participação e submersão da sociedade para o âmago da política. Urge, sobretudo nos países de democracia tardia ou ainda em fase de transição, a necessidade do fortalecimento das relações pacíficas de convívio e da organização de uma sociedade civil capaz de fortalecer as relações sociais internas, reivindicando a reforma política democrática dos Estados e o respeito dos fundamentos contratuais da soberania do povo.

Para tanto, também se faz necessário, como estratégia, uma pedagogia cívica, ética e moral, que promova a democracia como crença e valor político essenciais para romper com antigas práticas patriarcais, assistencialistas, clientelistas, desiguais, autoritárias e produtoras de violência e de criminalidade institucionais e estatais. 
Com efeito, em países cujos processos democráticos não ganharam a maturação necessária pelo povo, o que existem são regimes democráticos aparentes, que não respeitam nem conservam liberdades individuais, tampouco primam por uma convivência pacífica baseada na ética e na moral.

Desse modo e seguindo o raciocínio de Castel (2003, p. 271), mesmo com a instalação do Estado-nação liberal e com a Declaração Universal dos Direitos do Homem e do Cidadão, isso não redundou na emancipação ou na garantia da cidadania ativa aos trabalhadores, posto que, "em nome do direito que deve ser imposto a todos, os proletários devem ser de fato excluídos da cidadania plena".

A cidadania do homem mundial está apenas em esboço, pensada, prometida, imaginada. Assim, as organizações governamentais, tais como a Organização das Nações Unidas (ONU), a Organização das Nações Unidas para a Educação, a Ciência e a Cultura (Unesco) e outras, inclusive não governamentais, pouco podem fazer para concretizar a vigência dos direitos civis, políticos, econômicos, sociais e culturais em escala mundial. Conforme Ianni (2002, p. 111) "a Declaração Universal dos Direitos do Homem, promulgada pela ONU em 1948, permanece como uma declaração de intenções, de ideais, a despeito da sua importância social, política, econômica e cultural".

A agudização da globalização, alcançando o status neoliberal, e de sua pretensão de transformar o mundo numa aldeia global, atingiu em cheio as ciências penais. Assim, as práticas judiciárias, que sempre apareceram como imperturbáveis, sofreram alterações legislativas, principalmente para proteger interesses de classes dominantes e reprimir duramente aqueles que se desviem das normas do estatuto jurídico burguês.

Com o desenvolvimento do binômio globalização-neoliberalismo, as nações de economias periféricas ou subdesenvolvidas foram atingidas em cheio pelo aumento e desenvolvimento da violência e da criminalidade. Com o desenvolvimento do tripé economia-tecnologia-telecomunicação da era dita pós-industrial, além do auge do progresso e da ciência, ocorreu paralela e paradoxalmente uma evolução e uma expansão, nunca vistas antes, de toda sorte de violência e práticas criminosas, saltando do crime comum e do banditismo social para o crime organizado digitalizado (crime em rede de computação). 
Como aponta Giddens (1991), assim como a modernidade não se configura num projeto arquitetônico homogêneo, mas descontínuo, a globalização, com o endosso do neoliberalismo, configura-se num processo heterogêneo, pois, ao mesmo tempo que significa desenvolvimento para os que detêm a riqueza e os meios de produção, pauperiza a grande massa de trabalhadores que têm sua mão de obra desvalorizada em um contínuo processo de desqualificação do trabalho, desemprego, miséria social e produção de variados tipos de violência e de criminalidade.

Essas mudanças, conforme Harvey (1993), de uma mão de obra qualificada e requalificada para o sempre volátil e vulnerável capitalismo, têm provocado alterações profundas, causando uma nova organização social desde o final do século XX, cujas consequências têm sido a produção dos trabalhadores informais e os supranumerários, os desfiliados do mundo do trabalho formal e de suas garantias sociais. Sendo assim, na medida em que a sociedade marcha para um imbricamento em teias globais, os paradoxos e os dilemas também coexistem de forma complexa, perplexa e difusa.

Esse aprofundamento da interdependência entre as nações, povos, grupos, classes, regiões e indivíduos, por não ocorrer apenas na esfera político-econômica, mas também na social, simultaneamente integrativa e antagônica, tem multiplicado dilemas em escala global, quando verifica, por exemplo, a impossibilidade de evitar: guerras nucleares globais, catástrofes ecológicas, bem como controle da disseminação da Aids, das drogas e da violência organizada.

Conforme Sader e Gentili (1995), a produção de um exército de excedentes (trabalhadores sem trabalho), a precarização profissional, a exploração trabalhista e a produção dos inúteis para o mundo, ou supranumerários, levaram as grandes massas pobres à miséria social, à debilitação geral do Estado-nação e à impossibilidade de cumprir as promessas sociais saudáveis do discurso moderno/contemporâneo e do capitalismo em suas últimas instâncias.

A debilitação do Estado-nação e a impossibilidade de cumprir as promessas sociais saudáveis do discurso moderno e do capitalismo em sua fase aguda, a partir da década de 1970, sobretudo para os países de economia 
periférica, trouxeram como consequências: a produção de um exército de desempregados, a precarização profissional, a exploração trabalhista e a miséria social dos supranumerários, que, segundo Castel (2003, p. 531), "podem escolher entre a resignação e a violência esporádica".

O desenvolver desses ideais tornou-se incompatível, no âmbito geral, com o equilíbrio social necessário ao bem-estar da população. Nessa direção, não há outra busca se não a de uma nova ordem que acompanhe contínua e celeremente o conhecimento, a técnica, a razão, porém com equilíbrio econômico, político, social e cultural. Paralelamente ao avanço do capitalismo e do liberalismo econômico, pontuou-se também a ordem para se obter o progresso. Com efeito, seguimos pensando como Hobsbawm (1995, p. 393), que a "história dos vinte anos após 1973 é a de um mundo que perdeu suas referências e resvalou para a instabilidade e a crise".

\section{Conclusão}

O novo Estado burguês capitalista prima pelo desenvolvimento científico e pelo progresso de forma decisiva para atender ao seu projeto ocidental: as leis mercadológicas como determinantes de possível aldeia global sem qualquer fronteira restritiva. Por esse projeto, exige-se do tripé economia-tecnologia-telecomunicação o progresso a qualquer custo, sem se importar com os meios empregados. A lógica da nova classe social dominante é a ciência, a indústria e o progresso acima de tudo. O Estado deve ser mínimo para o social e máximo para o capital, o que ocasionou levantes e movimentos sociais em muitas partes do mundo.

Tais movimentos têm sido tratados, muitas vezes, como ilegítimos, ilegais e criminosos, tendo sustentação no aparato jurídico burguês. Isso porque as ciências jurídicas positivistas aclamadas pelo Estado-nação, sobretudo o direito penal, têm sido utilizadas como reguladoras e defensoras do estatuto burguês, em detrimento das necessidades e dos direitos sociais da massa popular trabalhadora.

Por outro lado, e concomitantemente ao desenvolvimento e ao progresso no âmbito do capitalismo sem rédeas e da globalização neoliberal, a violência 
difusa e a criminalidade também se desenvolvem e atingem o tecido social humano de forma degradante, em largas proporções.

O tripé economia-tecnologia-telecomunicação, implementado pela geopolítica capitalista, que busca transformar o mundo numa aldeia global neoliberal, favorecedora do desenvolvimento e do progresso espetaculares, trouxe consigo também problemas até então insolúveis, tais como: a possibilidade real e iminente de uma guerra nuclear, a cura da Aids e o aumento incontrolável da violência e da criminalidade.

A produção da miséria social em larga escala pela agudização capitalista neoliberal tem exigido, de forma intransigente e excludente, mão de obra qualificada e requalificada permanentemente. $O$ não atendimento às novas diretrizes dos mundos do trabalho tem como consequência imediata o desemprego, ou o subemprego, de levas de trabalhadores, formando sempre um exército de desempregados, indivíduos que, sem opção, barateiam sua mão de obra para poder sobreviver ganhando o mínimo ou se tornam supranumerários ou inúteis para o mundo.

\section{Referências}

BOURDIEU, Pierre. O poder simbólico. 5. ed. Rio de Janeiro: Bertrand Brasil, 2002.

CASTEL, Robert. A insegurança social: o que é ser protegido? Petrópolis: Vozes, 2005.

As metamorfoses da questão social: uma crônica do salário. Petrópolis: Vozes, 2003.

CHÂTELET, François; DUHAMEL, Olivier; PISIER-KOUCHNER, Evelyne. História das ideias políticas. Rio de Janeiro: Jorge Zahar, 2000.

COGGIOLA, Osvaldo. O capital contra a história: gênese e estrutura da crise contemporânea. São Paulo: Xamã/Pulsar, 2002.

GIDDENS, Anthony. As consequências da modernidade. São Paulo: Unesp, 1991.

GOMES, Abel Fernandes; PRADO, Geraldo; DOUGLAS, William. Crime organizado e suas conexões com o poder público: comentários à Lei n. 9.034/95: considerações críticas. Rio de Janeiro: Impetus, 2000.

HARVEY, David. A condição pós-moderna. São Paulo: Loyola, 1993.

HEGEL, Georg Wilhelm Fredrich. Princípios da filosofia do direito. São Paulo: Martins Fontes, 2003. 
HOBSBAWM, Eric. Era dos extremos: o breve século XX - 1914-1991. São Paulo: Companhia das Letras, 1995.

HOBBES, Thomas. Leviatã ou matéria: forma e poder de um Estado eclesiástico e civil. 2. ed. Sao Paulo: Abril Cultural, 1983.

IANNI, Octávio. A sociedade global. 10. ed. Rio de Janeiro: Civilização Brasileira, 2002.

KURZ, Robert. O colapso da modernização: da derrocada do socialismo de caserna à crise da economia mundial. 3. ed. Rio de Janeiro: Paz e Terra, 1993.

. Razão sangrenta: ensaios sobre a crítica emancipatória da modernidade capitalista e seus valores ocidentais. São Paulo: Hedra, 2010.

LOCKE, John. Segundo tratado do governo civil. São Paulo: Abril Cultural, 1983.

MORAES, Reginaldo. Neoliberalismo: de onde vem, para onde vai? São Paulo: Senac, 2001.

ROUSSEAU, Jean-Jacques. O contrato social. São Paulo: Russel, 2006.

SADER, Emir; GENTILI, Pablo (Orgs.). Pós-neoliberalismo: as políticas sociais e o Estado democrático. Rio de Janeiro: Paz e Terra, 1995.

VELHO, Gilberto. Mudança, crise e violência. Rio de Janeiro: Civilização Brasileira, 2002.

WEBER, Max. Ensaios de sociologia. 5. ed. Rio de Janeiro: LTC, 1982.

WIEVIORKA, Michel. O novo paradigma da violência. Tempo Social, São Paulo, v. 9, n. 1, p. 5-41, 1977.

\section{Sobre os autores}

ANTÔNIo RoBERTo XAVIER - Historiador, sociólogo e pedagogo.

E-mail: roberto@unilab.edu.br

Eduardo Ferreira Chagas - Filósofo. Professor doutor de Filosofia.

E-mail:ef.chagas@uol.com.br

Edilberto Cavalcante Reis - Historiador e Teólogo. Professor doutor de História.

E-mail: ecreis1968@gmail.com

Este é um artigo de acesso aberto distribuído nos termos de licença Creative Commons. (C) (i) 